\title{
A recepção do Modernismo brasileiro nos EUA: um estudo das antologias de poesia brasileira editadas por Elizabeth Bishop e John Nist
}

Eduardo Luis Araújo de Oliveira Batista

Resumo: A partir de uma abordagem que contempla as relações entre tra-
dução, antologização e crítica literária, este artigo investiga o papel das
reescritas (Andre Lefevere) na recepção do modernismo brasileiro nos
Estados Unidos. Para esse propósito, analisa os trabalhos realizados pela
poeta Elizabeth Bishop e pelo acadêmico John Nist, introdutores da litera-
tura modernista brasileira nos EUA. Bishop traduziu e editou uma antolo-
gia de poesia brasileira do século 20 em 1972; Nist também traduziu e
editou a própria antologia de poesia modernista brasileira em 1962, e foi o
autor do primeiro livro dedicado ao assunto publicado nos EUA, em 1967.

Palavras-chave: Elizabeth Bishop; John Nist; Modernismo Brasileiro; Recepção; Tradução Literária.

\section{Introdução}

Com a publicação de An Anthology of Twentieth Century Brazilian Poetry, em 1972, em que participou como editora e tradutora, a poeta norte-americana Elizabeth Bishop consolidou sua reputação como 
mediadora cultural entre o Brasil e os EUA e como divulgadora da moderna literatura brasileira em língua inglesa. Entre as décadas de 1950 e 1970, período em que viveu no Brasil, Bishop traduziu e publicou em inglês alguns de nossos melhores autores, e na antologia que editou é apresentada como tendo introduzido nossa poesia modernista nas publicações estadunidenses por meio de suas traduções de Carlos Drummond de Andrade e João Cabral de Melo Neto, publicadas respectivamente na revista Poetry, em 1963, e na Shenandoah, em 1965. Além desses textos, Bishop publicou traduções de três contos de Clarice Lispector em 1964 na Kenion Review. Seu corpus tradutório moderno brasileiro completa-se com versões em inglês de poemas de Manuel Bandeira, Joaquim Cardozo e Vinícius de Moraes, incluídas na antologia em que atuou como editora. A fama de Bishop como poeta, assim como seu longo envolvimento com o país, provavelmente ajudaram a tornar seu nome mais lembrado quando se fala em divulgação da literatura modernista brasileira nos EUA. No entanto, o precursor nessa divulgação é um nome menos conhecido, o tradutor e acadêmico John Nist, que também se dedicou a traduzir nossos escritores depois de uma passagem pelo país.

Nist publicou suas primeiras traduções de poemas de Manuel Bandeira, Cecília Meireles e Carlos Drummond de Andrade em 1959, no The Beloit Poetry Journal. Em 1962 publicou Modern Brazilian Poetry: An Anthology, além de treze traduções de poemas de Drummond também no The Beloit Poetry Journal. Em 1965 publicou uma coletânea de poemas de Drummond traduzidos por ele, In the Middle of the Road: Selected Poems of Carlos Drummond de Andrade, e traduções de três poemas de Manuel Bandeira na The Southern Review. Nist publicou também na década de 1960 uma série de artigos críticos sobre o Modernismo brasileiro, o Concretismo e sobre seus três poetas preferidos, Cecília Meireles, Bandeira e Drummond, textos reunidos no livro The Modernist Movement in Brazil: A Literary Study, de 1967, um dos primeiros livros sobre o movimento modernista brasileiro publicados nos EUA. Sua obra se completa com resenhas sobre livros brasileiros lançados nos EUA. 
O trabalho desses pioneiros, além de ter trazido mais visibilidade para nossa literatura no estrangeiro, ajudou a criar as bases para a recepção de nosso Modernismo no meio literário norte-americano. Propomos neste trabalho avaliar a ação pioneira de Bishop e Nist na divulgação de nossa literatura modernista na língua inglesa, por meio do estudo das práticas da tradução, antologização e crítica literária desenvolvidas por ambos, e como essas práticas ajudaram a criar uma tradição de leitura do nosso Modernismo que se difundiu na recepção de nossa literatura no estrangeiro. As práticas da tradução, antologização e crítica literária são aqui vistas como reescritas, segundo conceito do teórico Andre Lefevere (1992). Para Lefevere, as reescritas manipulam os textos literários para funcionarem dentro de uma dada cultura de uma determinada forma, refletindo a ideologia e a poética dos reescritores (editores, tradutores, críticos, historiadores, etc.). No caso de uma literatura estrangeira, as reescritas apresentam um potencial maior de manipulação, por recontextualizarem a obra num novo sistema literário e cultural. Essa manipulação se dá tanto pela seleção das obras a serem traduzidas, como pelos processos de tradução, de agrupamento em antologias, de historiografia e crítica literária. Essa série de reescritas procura adequar a obra a um novo público, em uma nova língua, ajudando essa obra a ocupar seu lugar em um sistema literário de diferente tradição, e influenciando em parte sua recepção.

\section{A recepção do Modernismo brasileiro nos EUA}

A obra de divulgação de nossa literatura modernista realizada por John Nist é mais extensa e variada que a realizada por Elizabeth Bishop, mas, a despeito de possíveis críticas à representatividade de ambas, a repercussão maior é mesmo de Bishop, como é possível ver em diversos depoimentos de estudiosos da área que avaliam a recepção de nossa literatura na língua inglesa. No final da década de 1970, criticando a dificuldade de encontrar textos de e sobre o Modernismo brasileiro no mercado americano, a pesquisa-

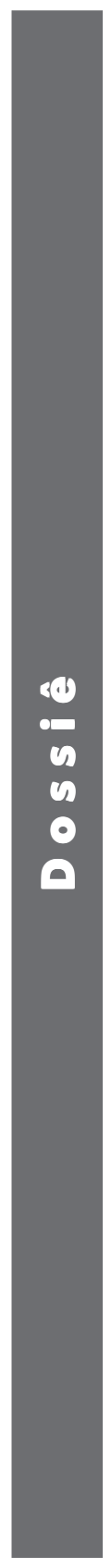


dora da obra de Mário de Andrade, Joan Rosalie Dassin, refere-se à antologia compilada por Bishop como "a primeira grande antologia norte-americana de poesia brasileira" (DASSIN, 1978, p. 88). Em seu estudo da literatura norte-americana produzida após a Segunda Guerra Mundial, publicado na década de 1980, Robert Kiernan também ressalta a importância de Bishop na divulgação de nossa literatura nos EUA, afirmando que "por muitos anos no Brasil, Bishop desempenhou também um importante papel ao traduzir os escritores brasileiros mais importantes e apresentá-los ao público norteamericano" (KIERNAN, 1983, p. 148). A mesma reverência é feita por Ashley Brown, também tradutor de autores brasileiros para a língua inglesa, segundo o qual "as traduções de Elizabeth Bishop [...] tornaram-se um padrão para aqueles que, como nós, se dedicaram à mesma tarefa" (BROWN, 1983, p. 237). João Almino, em seu balanço poético entre EUA e Brasil, escrito no final dos anos 1990, rende sua homenagem à ação de Bishop como mediadora entre as duas literaturas - "a ela [Bishop] se deve, em parte, a organização da única antologia de boa circulação e prestígio entre os meios norte-americanos interessados na cultura brasileira: An Anthology of Twentieth-Century Brazilian Poetry" (ALMINO, 1996, p. 7). Na introdução à antologia de Régis Bonvicino e Tarso de Melo publicada nos EUA em 2000, Lies About the Truth: 14 Brazilian Poets, Paul Hoover elege como as duas melhores antologias sobre poesia moderna brasileira publicadas nos EUA a citada antologia de Bishop e a antologia Nothing the Sun Could Not Explain, de 1997, também de co-autoria de Régis Bonvicino. Segundo ele, as duas são "as mais significativas recentes antologias da poesia brasileira em tradução para o inglês" (HOOVER, 2000).

Como podemos perceber pelas citações que apresentamos, a atuação de Bishop como tradutora de poetas brasileiros se confirmou através do tempo, e mesmo após três décadas sua antologia continua a ser citada como uma das mais significativas entre as "recentes" antologias de poesia brasileira publicadas em língua inglesa. Se Bishop é constantemente lembrada por aqueles que estudam 
as relações literárias entre Brasil e EUA, a obra de John Nist permanece à sombra, tendo sua existência muitas vezes desconhecida ou relegada ao segundo plano. Esses dados nos apontam a restrita presença de nossa literatura moderna traduzida em língua inglesa, o que torna algumas poucas antologias e textos publicados como referências únicas, empobrecendo e restringindo a recepção de nossa literatura no estrangeiro.

A dificuldade de encontrar obras modernistas brasileiras traduzidas em inglês durante o período de atuação dos dois tradutores citados pode ser entrevista no depoimento da norte-americana Dassin sobre sua pesquisa que gerou o livro Política e poesia de Mário de Andrade (1978). Dassin reclama da escassez de obras modernistas brasileiras publicadas nos EUA à época, e de seu relativo desconhecimento no país. Sobre a recepção da obra de Mário de Andrade - um dos principais teóricos, críticos e criadores do nosso Modernismo - nos EUA e, por extensão, do Modernismo brasileiro, Dassin descreve:

Embora haja poemas seus incluídos no Penguin Book of Latin American Verse (1971), haja outro em An Anthology of TwentiethCentury Brazilian Poetry (1972) de Elizabeth Bishop e Emanuel Brasil, e Jean Franco discuta-o em The Modern Culture of Latin America (1967), não existe nenhuma análise extensa em inglês [de seu trabalho]. Que eu saiba, há apenas três obras que tratam substancialmente de Mário de Andrade: The Modernist Movement in Brazil (1967) de John Nist; uma tradução de $O$ Movimento Modernista de Wilson Martins, feita por Jack E. Tomlins e intitulada The Modernist Idea (1970), e a tradução que Jack E. Tomlins também fez de Paulicéia Desvairada, The Hallucinated City (1958) [...] [E conclui:] Por isso, o leitor de fala inglesa não dispõe de fontes críticas e nem de recursos aos textos, uma vez que ainda não foram traduzidos à larga. Amar, verbo intransitivo (1927), obra relativamente sem importância, foi traduzida para o inglês em 1933 por Margaret Richardson Hallingsworthe, e foi publicada com o título de

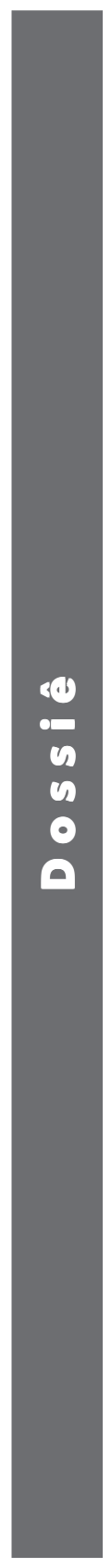


Eduardo Luis Araújo de Oliveira Batista. A recepção do Modernismo brasileiro nos...

Fräulein pela Macauly and Co. de New York. Em 06 de agosto o New York Times concedeu-lhe uma review favorável. (DASSIN, 1978, p. 117)

Se Dassin fosse realizar sua pesquisa atualmente, apesar da maior disponibilidade de textos críticos sobre Mário em inglês, se surpreenderia ao encontrar apenas uma nova obra traduzida do autor para acrescentar à sua lista: Macunaíma (1928), publicado em língua inglesa em 1984 (BARBOSA, 1994). Como comenta Almino em seu Balanço poético Brasil-EUA (1997) sobre a pouca representação dos escritores brasileiros nos EUA, "nem mesmo os maiores poetas brasileiros deste século, como Bandeira, Drummond, Murilo Mendes e João Cabral de Melo Neto têm recebido a atenção merecida nos EUA. Basta dizer que só recentemente, em 1994, foi publicada a primeira antologia da poesia de João Cabral (Selected Poetry, 1937-1990, Wesleyan University Press)" (ALMINO, 1997, p. 7). Outros estudiosos, como o brasilianista Richard Morse, reclamam da deficiência dos estudos acadêmicos na área. Segundo ele, "é comum dizer-se, por exemplo, que no meio acadêmico americano praticamente não há lugar para qualquer atividade intelectualmente madura no âmbito da história da literatura ou da crítica literária latino-americana" (MORSE, 1990, p. 211).

Apesar da presença da tradução do livro de Mário de Andrade, citada por Dassin, já na década de 1930, a recepção de nosso Modernismo nos EUA, seja através de traduções e de edição de antologias, seja por meio de trabalhos críticos, só se deu de forma mais efetiva a partir da década de 1950. Segundo Antonio Candido (CANDIDO, 1995, p. 11), o primeiro artigo em língua inglesa sobre o Modernismo brasileiro foi publicado pelo brasilianista Richard Morse na revista The Hudson Review em 1950, intitulado "Brazilian Modernism". O próprio Candido publicou um artigo sobre a literatura moderna brasileira, "Modern Writing in Brazil," no Atlantic Monthly Supplement, em 1956. Porém, é a partir da década de 1960 que surgem mais artigos e livros sobre o tema. Parte desse interesse pode 
ser atribuído à aproximação entre os dois países intensificada nesse momento por meio da Aliança do Progresso, política criada pelos EUA para estreitar seus laços com os países do continente americano, e que se utilizou de diversos programas de intercâmbio cultural, entre eles projetos de tradução e estudos acadêmicos. ${ }^{1}$ Outra razão deve-se à fama que o movimento brasileiro da Poesia Concreta adquiriu nos meios literários internacionais à época, o que ajudou a trazer visibilidade para a literatura brasileira e para seu movimento modernista, ao qual os críticos estadunidenses trataram logo de vincular a nova proposta poética concretista, como veremos adiante. Esses primeiros estudos acadêmicos sobre nosso Modernismo, escritos por Candido e Morse, foram logo seguidos pelas publicações das primeiras antologias de poesia.

Para Lefevere, a antologização de obras de uma literatura estrangeira é uma das práticas culturais em que o poder das reescritas mais se potencializa, uma vez que encontramos uma cadeia de reescritas, uma emoldurando a outra. Em antologias de poesias, que são as mais editadas por motivos óbvios de praticidade, encontramos uma sequência de poemas, retirados dos livros em que foram originalmente publicados, e distantes das outras peças que os circundavam, reunidos a poemas de diversos outros autores, estabelecidos em uma sequência aleatória, traduzidos para uma nova língua e apresentados por textos introdutórios que justificam sua presença naquele conjunto. Numa estrutura em abismo, o poema é escolhido, traduzido, explicado, e relacionado a outros poemas de outros autores. Considerando que as antologias são tradicionalmente utilizadas como livros de consulta em cursos universitários, seu poder de criar e divulgar a imagem de uma literatura torna-se ainda maior. Para Lefevere, as antologias são publicadas em momentos em que a cultura fonte está em destaque. Desse ponto de vista, entende-se por que as antologias de poesia moderna brasileira em língua ingle-

A esse respeito ver o artigo: BATISTA, Eduardo L. A. O. Representação cultural brasileira no estrangeiro: a presença da literatura de viagem e da tradução nas relações culturais Brasil-EUA. Moara, Belém do Pará, V. 25, p. 176-192, 2006.

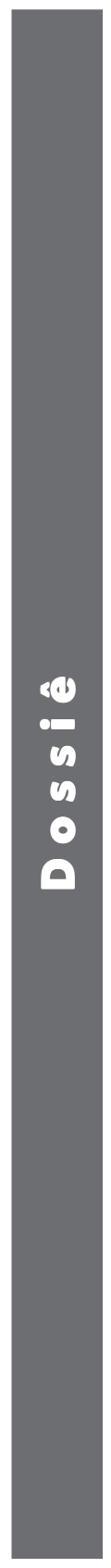


sa só surgiram no período pós II Guerra Mundial, quando interesses políticos e econômicos colocaram o Brasil em evidência na política externa estadunidense.

Assim, a primeira antologia do modernismo brasileiro em língua inglesa surgiu apenas em 1954, An introduction to Modern Brazilian Poetry: Verse Translations, editada e traduzida por Leonard Downes. Em seguida foram publicadas: a antologia de Nist, Modern Brazilian Poetry: An Anthology, lançada em 1962; An Anthology of Concrete Poetry, editada por Emmett Williams em 1967; An Anthology of Brazilian Modernist Poetry, editada por Giovanni Pontiero em 1969; Poesia brasileira moderna. A bilingual anthology, editada por José Neistein em 1972; mesmo ano da publicação de An Anthology of Twentieth Century Brazilian Poetry, editada por Elizabeth Bishop e Emanuel Brasil. Apresentamos a seguir uma análise separada das antologias de Nist e Bishop, para em seguida estabelecermos um paralelo entre os textos e a imagem de nosso Modernismo apresentados pelos dois reescritores.

\section{John Nist}

A antologia de Nist lançada em 1962 pela editora da Universidade de Indiana, Modern Brazilian Poetry: An Anthology, apresenta obras de doze poetas, agrupados, segundo o editor, nas diferentes fases do movimento. Nist divide o Modernismo brasileiro em quatro fases. A primeira fase, entre 1920-30, marcada pela ironia e sátira, seria representada por Mário de Andrade, Manuel Bandeira e Cassiano Ricardo. A segunda fase, entre 1930-40, seria caracterizada por duas tendências: a sócio-política, representada por Carlos Drummond de Andrade, e a religioso-mística, representada por nomes como Murilo Mendes, Augusto Frederico Schmidt e Cecília Meireles. A terceira fase, que vai de 1940 a 1950, tem como representantes os poetas Vinícius de Moraes, Jorge de Lima e Domingos da Silva, que teriam sido influenciados por T. S. Eliot e o New Criticism, através do trabalho com as metáforas e a preocupação com a forma e o ritmo. A quarta e última fase se iniciaria nos anos 1950 e estaria em prosse- 
guimento na década de 1960, quando o volume foi lançado, tendo sido afetada por Ezra Pound, e.e. cummings, os concretistas suíços e os calligrammes de Apollinaire. Como dois exemplos dessa fase concretista, Nist inclui João Cabral de Melo Neto e Paulo Bonfim. Esses doze poetas citados formam a antologia editada e traduzida por Nist.

Se a antologia de Nist foi a segunda publicada nos EUA a contemplar nossos poetas modernistas, seu estudo The Modernist movement in Brazil pode ser considerado o primeiro livro publicado naquele país a tratar exclusivamente desse momento importante de nossa história literária. Anteriormente a esse lançamento, podemos encontrar apenas referências ao movimento modernista nos panoramas da literatura brasileira apresentados por Érico Veríssimo em seu Brazilian Literature: An Outline, de 1945, livro fruto de seus cursos sobre literatura brasileira nas universidades americanas, ou ainda em Marvelous Journey: Four Centuries of Brazilian Literature, de Samuel Putnam, publicado em 1948, em que dedica algumas páginas ao movimento. Em seu estudo sobre o Modernismo brasileiro publicado em 1967, John Nist aborda da semana de arte moderna de 1922 ao movimento concretista, buscando antecedentes do movimento no Romantismo do século 19. O interesse em estudar nosso Modernismo não é apenas literário, como o próprio autor afirma, ao destacar, no prefácio do livro, outras preocupações presentes em sua tarefa: "qualquer movimento cultural defendendo intenções tão altas como essas é válido de se estudar; quando ele diz respeito à mais importante nação na América do Sul e a um país-chave na defesa democrática da dignidade e liberdade humanas, o estudo se torna imperativo" $^{\prime \prime}$ (NIST, 1967, p. 4), revelando a mistura de interesses literários e políticos que permeavam as relações culturais naquele momento da Guerra Fria.

Nist elege como os quatro maiores escritores do movimento Manuel Bandeira, Carlos Drummond de Andrade, Jorge de Lima e, em suas palavras, "a maior poeta na língua portuguesa"ii (Ibid., p. 161), Cecilia Meireles. Numa segunda escala cita cinco autores: Murilo Mendes, Augusto Frederico Schmidt, Vinícius de Moraes,

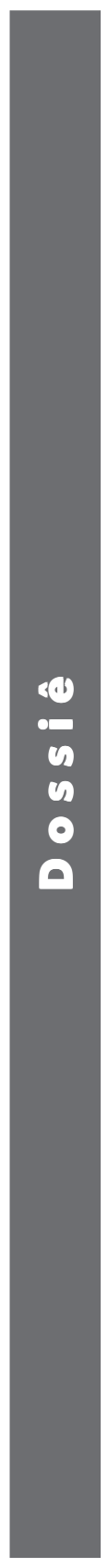


Cassiano Ricardo e Domingos Carvalho da Silva. Em sua opinião, "dos cinco, o mais brasileiro em seu trabalho é Murilo Mendes" (Ibid., p. 162), sem explicitar quais características presentes na obra de Murilo o tornam tão brasileiro aos seus olhos. Seus maiores elogios vão para Drummond, considerado "uma das maiores vozes líricas do hemisfério ocidental durante o século vinte"iv (Ibid., p. 145). Nessa avaliação de nossos escritores, é bom lembrar que, apesar do título abrangente de sua obra, Nist contempla apenas o estudo da poesia, deixando a prosa em segundo plano. Para ele, os maiores avanços do Modernismo teriam se dado no campo da poesia. Sua avaliação do Concretismo não é muito favorável, encarando os experimentalismos formais dos concretistas como uma prática "juvenil e primitiva" (Ibid., p. 189). O que para alguns poderia ser considerado como uma das inovações do Concretismo, como a simultaneidade tempo/espaço e o diálogo com o design e a propaganda, Nist vê como algo depreciativo: "em sua realizada simultaneidade (temporal e espacial) a poesia concreta (...) adquire a vulgaridade da propaganda" (Idem), e conclui, selando sua opinião sobre o assunto: "Ela [a poesia concreta] peca por ser na maior parte obra de jovens rebeldes que se levam tão a sério a ponto de não lhes sobrar severidade de julgamento com o qual informar seus poemas. $\mathrm{O}$ resultado parece ser a morte do movimento modernista no Brasil $(. . .)^{\prime \prime v}$ (Idem). Nist não apenas nega a possibilidade de apreciação estética do Concretismo, como ainda o responsabiliza pela morte do Modernismo brasileiro. Nist mantém aqui a divisão do Modernismo em quatro fases, como já havia apresentado na antologia de 1962. Novamente mostra uma visão um pouco confusa do que chama de duas últimas fases do Modernismo, a Geração de 1945 e o Concretismo. Segundo ele, a respeito da "terceira fase", entre 1940-50, "a preocupação com a forma, com o ritmo e as palavras, sob a liderança de Cecília Meireles, combinou-se com a influência de T. S. Eliot e do New Criticism na América para produzir uma estética que favoreceu a criação da forma pura"vi (Ibid., p. 109). E inclui nesse grupo João Cabral de Melo Neto e Vinícius de Moraes. Esses dois últimos 
nomes estariam ligados ao desenvolvimento da fase seguinte, o Concretismo: "Em suas tentativas de criar imagens que não se abalam sob o peso da realidade, João Cabral tem sido uma influência formal sobre o desenvolvimento da quarta fase do movimento modernista no Brasil, o Concretismo, unindo sua influência à dos precursores Vinícius de Moraes e Oswald de Andrade (...)" (Ibid., p. 182). O Concretismo, segundo ele, seria um prolongamento do movimento modernista: "ao estender as realizações de seus predecessores, os Concretistas continuam uma fase no padrão evolutivo do movimento Modernista no Brasil"vii (Ibid., p. 109).

\section{Elizabeth Bishop}

A antologia de poesia brasileira dirigida por Elizabeth Bishop, em co-edição com o brasileiro Emanuel Brasil contém, em suas palavras, "seleções do trabalho de quatorze poetas da geração moderna e da geração de 1945 (...). Inevitavelmente, ela é mais representativa dos gostos pessoais dos editores" viii (BISHOP, 1972, p. XV). Nela encontramos traduções de poemas de Manuel Bandeira, Oswald de Andrade, Jorge de Lima, Mário de Andrade, Joaquim Cardozo, Cecília Meireles, Murilo Mendes, Carlos Drummond de Andrade, Mauro Ramos da Mota, João Cabral de Melo Neto, Marcos Reis e Ferreira Gullar. Como parte de um projeto da Wesleyan University, havia a idéia de um segundo volume, que conteria traduções de poemas concretistas e letras de músicas da MPB da década de 1970. Com a morte de Bishop, em 1979, o projeto foi concluído por Emanuel Brasil e William Jay Smith, que editaram a antologia Brazilian Poetry (1950-1980), pela Wesleyan University, em 1983.

Na introdução à antologia, assinada apenas por Bishop e onde apresenta um pequeno resumo da história literária brasileira, a escritora resume o movimento modernista como uma tentativa de abandono da "linguagem literária obsoleta"ix do século 19, e uma busca de se escrever poesia na linguagem coloquial: "muito da poesia dos anos 1920 tentou isso, usando gíria, abreviações, elipses e

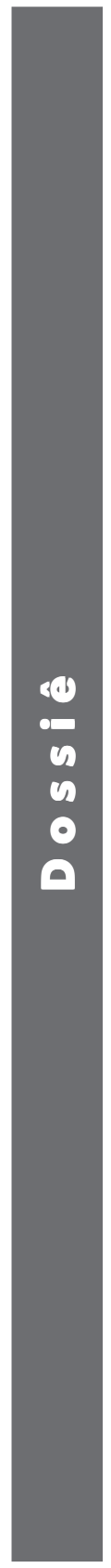


Eduardo Luis Araújo de Oliveira Batista. A recepção do Modernismo brasileiro nos...

apóstrofes para indicar letras ou sílabas esquecidas na fala coloquial. Bastante parecido com o que aconteceu na poesia em língua inglesa uma década antes"x (Ibid., p. XV). Comentando sobre o movimento lançado em 1922 e suas consequências imediatas, Bishop elege a obra de Oswald de Andrade, Pau Brasil (1924), como modelo da estética do movimento, evidenciando sua extrema economia de meios, a linguagem simples na abordagem de temas brasileiros, e o tom humorístico. Qualidades que, considera ela, "têm marcado a poesia brasileira desde então, elas representam a real conquista da Semana de Arte Moderna e do Modernismo"xi (Ibid., p. XX). Concordando com Nist, Bishop também considera Drummond como o mais importante poeta brasileiro contemporâneo. Apesar de suas traduções e elogios a escritores brasileiros como Clarice Lispector, Drummond e João Cabral de Melo Neto, Bishop não demonstra muito interesse por nosso movimento modernista, considerado como uma cópia um pouco atrasada do que ocorreu na Europa e nos EUA alguns anos antes. Em uma entrevista concedida a Ashley Brown quando ainda morava em Petrópolis, e publicada em 1966, nos EUA, Bishop comenta sobre o Modernismo brasileiro. Indagada por Brown sobre o que ela quis dizer ao afirmar que a poesia em língua inglesa havia caminhado por uma direção diferente da poesia brasileira, Bishop responde:

O que aconteceu com Eliot e Pound logo em 1910 - o Modernismo. A poesia brasileira é muito mais formal que a nossa ela é mais distante do popular. É verdade que eles tiveram um movimento modernista em 1922, liderado por Mário de Andrade e outros. Mas eles ainda não escrevem do modo que falam. E eu suponho que eles nunca escaparam do Romantismo (BISHOP, 1996, p. 19). ${ }^{\text {xii }}$

É essa visão da literatura brasileira, considerada atrasada e formal, que Bishop acaba revelando na antologia por ela editada. As inovações trazidas pela década de 1920, segundo ela, teriam declinado nas décadas seguintes: "poesia dos anos quarenta, cinquenta e 
sessenta, visualmente, pelo menos, é mais convencional do que aquelas primeiras tentativas modernistas" (BISHOP, 1972, p. XVI), provavelmente se referindo à Geração de 45, e deixando de lado o movimento concretista. Com relação ao Concretismo, Bishop partilha com Nist a opinião de que o movimento não deve ser levado muito a sério. Nesse estilo diz gostar apenas de e.e. cummings: "a poesia concreta que os outros poetas fazem eu não acho interessante. Tem apenas um impacto inicial - um jogo de palavras, às vezes divertido e espirituoso, mas inútil e impossível de se lembrar" (BISHOP, 1996, p. 52). Em carta de 1962 ao poeta Robert Lowell, em visita ao Brasil, diz, a respeito do movimento: "Vão lhe mostrar uma coisa horrível chamada neoconcretismo - puro Paris anos 20. [...] É este o problema - são tão provincianos, os jovens saem pela tangente e fazem redescobertas inúteis - e os velhos se acomodam com muita facilidade" (BISHOP, 1995, p. 719).

\section{Diferentes visões do Modernismo brasileiro}

A visão histórica do movimento modernista brasileiro, que parece surgir com Nist, e que propõe uma diferente periodização do movimento, estendendo-o à década de 1960, é encontrada em outros editores de antologias e críticos nos EUA, que buscam nos autores modernistas a chave para o entendimento do Concretismo brasileiro. A busca de precursores do Concretismo na tradição modernista pode ser encontrada em diversos artigos da época, como "Brazilian Concretism", de 1964, publicado por John Nist na Hispania, "Some formal types in the poetry of Mário de Andrade", de 1965, publicado na Luso-Brazilian Review por David W. Foster, e "Graphics, Phonics and the 'Concrete universal' in Manuel Bandeira's Concretist poetry”, de 1966, publicado na mesma revista por Gary Brower. No primeiro artigo, Nist sugere Vinícius de Moraes como uma ponte entre os concretistas e os primeiros modernistas, e considera o Concretismo como a quarta fase do Modernismo brasileiro. No segundo artigo, Foster busca os antecedentes do Concretismo na primeira 
Eduardo Luis Araújo de Oliveira Batista. A recepção do Modernismo brasileiro nos...

fase do Modernismo, e vê Mário de Andrade como seu precursor, através de sua preocupação com o estilo poético e a linguagem, "totalmente separada do conteúdo". Já no terceiro artigo citado, Brower filia Manuel Bandeira ao movimento concretista, e afirma que "Bandeira tem provavelmente expressado o concreto e o universal mais profundamente do que qualquer membro do movimento" (BROWER, 1966, p. 32).

A defesa dessa visão histórica do nosso movimento modernista no meio literário norte-americano acabou gerando uma certa polêmica entre os defensores dessa idéia e o estudioso brasileiro Wilson Martins, que atuou como professor universitário de literatura brasileira nos EUA entre 1962 e 1991, e teve alguns de seus livros publicados em língua inglesa. Em resenha publicada no The Modern Language Journal, em 1971, sobre a publicação da obra An Anthology of Brazilian Modernist Poetry, editada por Giovanni Pontiero em 1969, Wilson Martins critica exatamente essa ideia historicista apresentada na antologia. Segundo ele, entre outras críticas feitas ao livro,

[...] mais sério, e totalmente inaceitável para mim é propor a "fase construtiva do Modernismo" (p. 14) à qual pertenceriam poetas como João Cabral de Melo Neto e a chamada Geração de 45. De fato, como pode ser visto em meu livro $O$ Modernismo (1965), o movimento modernista terminou precisamente em 1945, com a morte de Mário de Andrade e outros eventos; a Geração de 45 define-se tão pouco como uma geração modernista a ponto de parecer uma oposição ao movimento. (MARTINS, 1971, p. 198).

Martins volta a fazer a mesma crítica, em sua resenha na revista Hispania, de 1976, dessa vez dirigida a Claude Hulet e seu extenso estudo Brazilian Literature, publicado em três volumes em 1975. Apesar de considerar o livro de Hulet como "o mais completo e atualizado de todos os manuais de literatura brasileira atualmente [na década de 1970] disponíveis nos Estados Unidos", Martins não 
deixa de criticar a inclusão de uma terceira fase do Modernismo entre 1945 e 1960, que considera como um erro conceitual de Hulet e outros críticos, ao entenderem "por programaticamente modernista o que é simplesmente moderno" (MARTINS, 1976, p. 59).

Nist, por seu lado, ao resenhar na The Spanic American Historical Review, em 1972, a edição em língua inglesa do livro de Wilson Martins, The Modernist Idea, lançado nos EUA em 1970, toca no mesmo assunto, mas defendendo seu ponto de vista inverso e criticando a ausência do que ele chama de últimas fases do Modernismo brasileiro, a Geração de 45 e o Concretismo, na obra de Martins: "ao limitar o movimento modernista em três décadas (1916-45), o Sr. Martins exclui as últimas fases de evolução do movimento e falha em distinguir completamente os grandes dos pequenos" 1972, p. 177). Em outra resenha ao mesmo livro de Martins, escrita por Mary L. Daniel e publicada no The Modern Language Journal, em 1972, a autora toca no assunto de forma oblíqua: "o legado do Modernismo é, com certeza, ainda bastante presente na cultura brasileira, ainda que o movimento em si seja geralmente tido como terminado em 1945 (...) de forma que a perspectiva histórica do movimento ainda está em formação" xiv (DANIEL, 1972, p. 97). Ao reconhecer a presença do Modernismo brasileiro na produção de então, e afirmar a indefinição dos limites históricos do movimento, a articulista critica de forma indireta a periodização proposta por Martins, questionando ainda a ausência da menção à presença do Concretismo na obra de Drummond, reforçando a busca de antecessores imediatos do movimento concretista no Modernismo, como havíamos notado anteriormente.

Essa visão que estende o Modernismo até a década de 1960 encontrou em Nist um dos defensores mais ferrenhos. Nist não defende apenas a inclusão das duas novas fases (Geração de 45 e Concretismo) no Modernismo brasileiro, mas apresenta uma visão evolutista do movimento, segundo a qual cada fase geraria a fase seguinte, em um desenvolvimento histórico progressivo e linear. Conforme essa visão, o movimento modernista brasileiro teria sur-

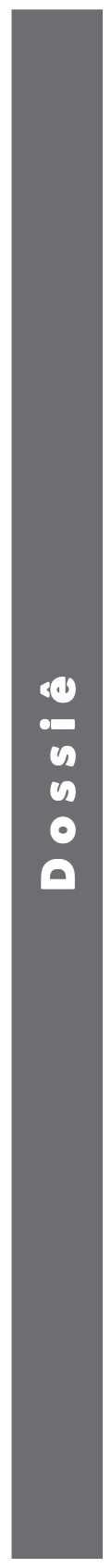


gido em sua primeira fase como uma ruptura total com a forma poética rígida estabelecida pelo Parnasianismo, para, através das três fases seguintes, ir aos poucos esmerando a forma poética até finalmente chegar à poética da forma pura, o Concretismo. É nesse sentido que podemos entender o padrão a que se refere, quando em seu livro The Modernist Movement in Brazil afirma que "ao estender as realizações de seus predecessores, os Concretistas continuam uma fase no padrão evolutivo do movimento Modernista no Brasil" ${ }^{\prime \times v}$ (NIST, 1967, p. 109). Esse padrão que Nist propõe percorreria uma evolução "da rebeldia da ausência de forma à exaltação do padrão e da forma"xvi (Ibid., p. 112). Em suas palavras, o movimento demonstraria "[...] uma evolução do espírito polêmico e nacionalista do Romântico ao espírito formalista e estético dos Neoclássicos" xvii (Idem). É nesse sentido que surgem tantos textos e interpretações que buscam nos escritores modernistas das gerações imediatamente predecessoras os precursores do Concretismo, seja em Mário de Andrade, Manuel Bandeira, Vinícius de Moraes e João Cabral, quando os próprios criadores do movimento concretista, como os irmãos Campos, preferem firmar sua tradição em Oswald de Andrade, Cruz e Sousa e Sousândrade. Essa necessidade de filiação entre os escritores e a geração que lhe antecede é justificada por e justifica a visão evolutiva do movimento apresentada por Nist.

\section{Conclusão}

Como podemos ver, John Nist e Elizabeth Bishop concordam em muitos pontos em suas visões do Modernismo brasileiro: ambos consideram a poesia modernista brasileira como de melhor qualidade e mais "avançada" que a prosa do mesmo período; ambos elegem Drummond como seu poeta preferido, ainda que Bishop às vezes coloque-se a favor de João Cabral; e ambos olham com desconfiança para a proposta dos concretistas, considerada como uma ideia inconsequente e vazia. Em outros pontos, eles divergem. Nist dá pouca ênfase à obra de Oswald de Andrade em seu tratado sobre 
o Modernismo, apresentando-o antes como um agitador e articulador do movimento do que como um escritor ou pensador. Segundo Nist, "tornando-se mais agressivo com os anos, Oswald fundou, em maio de 1928, a Revista de Antropofagia [Review of Canibalism, na tradução de Nist], uma revista que levou os elementos negativos e destrutivos do Modernismo brasileiro aos últimos limites e ajudou a assegurar a Oswald o lugar de playboy permanente das letras brasileiras" xviii (NIST, 1967, p. 79). Bishop, por outro lado, considera a poesia de Oswald como modelo da estética do movimento e a ele atribui as maiores conquistas poéticas do movimento. Com relação aos limites e periodização do movimento os dois tradutores e editores também divergem. Bishop parece seguir o padrão apresentado pelos críticos brasileiros, que datam o fim do Modernismo entre 1945 e 1955, o qual seria seguido cronologicamente pela Geração de 45, que aparece como um movimento autônomo, ainda que tributário do Modernismo, e seguido pelo Concretismo. É curiosa a proposta de Bishop de incluir letras da MPB no segundo volume da antologia, o que revela seu gosto pela música brasileira, tendo já publicado traduções de sambas. Nist, por sua vez, defende a idéia de que o movimento modernista brasileiro teria se estendido até a década de 1970, incluindo no período tanto a Geração de 45 quanto o movimento concretista.

Apesar das divergências entre as duas abordagens, e das possíveis críticas a serem feitas a ambas, Nist e Bishop foram importantes divulgadores de nossa literatura nos países falantes da língua inglesa, e seus trabalhos continuam a repercutir na recepção de nossa literatura no estrangeiro. Seria interessante fazer um estudo da recepção atual de nossa literatura modernista em língua inglesa, para a compararmos a essa primeira recepção e avaliarmos em que medida essa leitura proposta por Nist e Bishop de um movimento tão importante para nossa literatura evoluiu através do tempo. 
Eduardo Luis Araújo de Oliveira Batista. A recepção do Modernismo brasileiro nos...

\section{Referências}

ALMINO, João. Brasil / Estados Unidos: balanço poético. São Paulo: Fundação Memorial da América Latina, 1996.

BARBOSA, Heloísa Gonçalves. The virtual image: Brazilian literature in English translation. 1994. 500 f. 2 v. Tese (PhD) Centre for British and Comparative Cultural Studies, University of Warwick, 1994.

BISHOP, Elizabeth. Three stories by Clarice Lispector. "The smallest woman in the world", "A hen", e "Marmosets". Kenyon Veriew, Summer, 1964.

BRASIL, Emanuel. An anthology of twentieth century Brazilian poetry. Wesleyan University Press, 1972.

Uma arte. As cartas de Elizabeth Bishop. Org. Roberto Giroux. Trad. Paulo Henriques Britto. São Paulo: Cia. das Letras, 1995.

Conversations with Elizabeth Bishop. Ed. George Monteiro. Jackson: University Press of Mississippi, 1996.

BONVICINO, Régis. MELO, Tarso M. de. Lies about the truth: a postmodern Brazilian poetry anthology from 50s on. (14 Brazilian poets) New American Writing. n. 18, 2000.

BROWER, Gary. Graphics, Phonics and the 'Concrete universal' in Manuel Bandeira's Concretist poetry. Luso-Brazilian Review, V. 3, n. 1, p. 19-32, summer 1966.

BROWN, Ashley. Elizabeth Bishop in Brazil. In: SCHWARTZ, Lloyd. ESTESS, Sybil (Ed.) Elizabeth Bishop and her art. Ann Harbor: The University of Michigan Press, 1983. p. 223-40.

CANDIDO, Antonio. Modern writing in Brazil. In Perspectives of Brazil. Edited by Carleton Sprague Smith. Atlantic Monthly Supplement, p. 48-52, 1956.

Introdução. In: MORSE, Richard. O espelho de Próspero. Cultura e idéias na América. Trad. Paulo Neves. São Paulo: Cia. das Letras, 1995. p. 11.

DANIEL, Mary L. Review of The Modernist idea by Wilson Martins. Trad. Jack E. Tomlins. The Modern Language Journal, V. 56, n. 2, p. 97-98, February 1972.

DASSIN, Joan Rosalie. Política e poesia em Mário de Andrade. Trad: Antonio Dimas. São Paulo: Duas Cidades, 1978. 
DOWNES, Leonard S. An introduction to modern Brazilian poetry: verse translations. SP: Clube de Poesia do Brasil, 1954.

FOSTER, David William. Some formal types in the poetry of Mário de Andrade. Luso-Brazilian Review, V. 2, n. 2, p. 75-95, winter 1965.

HOOVER, Paul. Introduction. In: BONVICINO, Régis. MELO, Tarso M. de. Lies about the truth: a post-modern Brazilian poetry anthology from 50's on. (14 Brazilian poets) New American Writing. n. 18, 2000.

JOHNSON, Harvey L. The Brazilian mirror: some Brazilian writings in English translation. The Americas, V. 21, n. 3, p. 274-94, January 1965.

KIERNAN, Robert F. A literatura americana pós-1945. Um ensaio crítico. Rio de Janeiro: Nórdica, 1983.

LEVEFERE, Andre. Translation, rewriting and the manipulation of literary fame. London: Routledge, 1992.

MARTINS, Wilson. The modernist idea. A critical survey of Brazilian writing in the twentieth century. Trad. Jakc E. Tomlins. New York: New York University Press, 1970.

Review of An anthology of Brazilian modernist poetry by Giovanni Pontiero. The Modern Language Journal, V. 55, n. 3, p. 198, March 1971.

Review of Brazilian literature by Claude Hulet. Hispania, V. 59, n. 3, p. 556, September 1976.

MORSE, Richard. Brazilian modernism. The Hudson review, V. 3, n. 3, p. 447-52, 1950.

A volta de McLuhanaíma. Cinco estudos solenes e uma brincadeira séria. Trad. Paulo Henriques Britto. São Paulo: Cia. das Letras, 1990.

NIST, John. Modern Brazilian poetry: an anthology. Bloomington: Indiana University Press, 1962. 1963. The poetry of Cecilia Meireles. Hispania, V. 46, n. 2, p. 252-58, May

Contemporary Brazilian poetry. Books Abroad, V. 37, n. 3, p. 245-51, Summer, 1963.

Brazilian Concretism. Hispania, V. 47, n. 4, p. 711-15, December, 1964.

The Modernist movement in Brazil. A literary study. Austin: University of Texas Press, 1967. 
Eduardo Luis Araújo de Oliveira Batista. A recepção do Modernismo brasileiro nos...

Review of The Modernist idea: a critical survey of Brazilian writing in the twentieth century by Wilson Martins. Trad. Jack E. Tomlins. The Hispanic American Historical Review, V. 52, n. 1, p. 176-78, February 1972.

PONTIERO, Giovanni. An anthology of Brazilian modernist poetry (Commonwealth and International Library, Nuclear Engineering). Pergamon, 1969.

PUTNAM, Samuel. Marvelous journey: four centuries of Brazilian literature. New York, Knopf, 1948.

VERÍSSIMO, Érico. Brazilian literature: an outline. New York: The MacMillan Co., 1945.

WILLIAMS, Emmett (Ed.). An anthology of concrete poetry. New York: Something Else Press, 1967.

WOODBRIDGE, Hensley C. A bibliography of Brazilian poetry in English translation. Luso-Brazilian Review, V. 5, Supplementary Issue, p. 161-88, Summer 1978.

\section{Notas}

i Esta e outras traduções de citações foram feitas pelo autor deste artigo. No original: "Any cultural movement supporting such high intentions as these is worthy of study; when they concern the most important nation in South America and a key country in the democratic defense of human dignity and freedom, the study becomes imperative".

ii "The greatest woman poet in the Portuguese language".

iii "Of the five, the most Brazilian in his work is Murilo Mendes".

iv "One of the major lyric voices in the western hemisphere during the twentieth century".

v "In its achieved simultaneity (temporal and spacial) Concretist poetry [...] takes on the vulgarity of propaganda. [...] It suffers from the being largely the work of young rebels who take themselves so seriously that they have no severity of judgment left in which to inform their poems. The result seems to be the death of the Modernist movement in Brazil".

vi "In his attempts to create images that will not shatter under the burden of reality, João Cabral has been a formal influence upon the course of the fourth phase of the Modernist movement in Brazil, that of Concretism. As such in influence, he becomes a fellow forerunner with Vinícius de Moraes and with Oswald de Andrade".

vii "By extending the achievement of their predecessors, the Concretists remained a part of the evolving pattern of the Modernist movement in Brazil".

viii "Selections from the work of fourteen poets of the modern generation and of the postwar generation of 1945 [...]. Inevitably, it is more representative of the editors' personal tastes than all inclusive".

ix "Dead literary language". 
x "Much poetry of the '20s attempted this, using slang, abbreviations, ellipses, and apostrophes to indicate letters or syllables left out in ordinary, rapid speech. Very much the same thing that happened in English poetry a decade earlier".

xi "Have marked Brazilian poetry ever since; they represent the real achievement of Modern Art Week and Modernism".

xii "What happened with Eliot and Pound as early as 1910 - modernism. The Brazilians" poetry is still more formal than ours it's farther the demotic. It is true, of course, that they had a modernismo movement in 1922, led by Mario de Andrade and others. But they still don't write the way they speak. And I suppose they have never quite escaped from romanticism".

xiii "By limiting the Modernist movement to three decades (1916-1945), Sr. Martins cuts himself off from later phases of evolution within the movement and thus fails to fully distinguish the giants from the pygmies".

xiv "Modernism's legacy is, of course, still very present in Brazilian culture, even though the 'movement' itself is usually thought of as running its course by 1945. [...] So the historical perspective of the movement is yet in formation".

xv "By extending the achievement of their predecessors, the Concretists remained a part of the evolving pattern of the Modernist movement in Brazil".

xvi "From revelry in shapelessness to the exaltation of pattern and form".

xvii "An evolution from the nationalistic and polemical spirit of the Romantic to the formalistic and aesthetic spirit of the Neo-Classic".

xviii "Becoming more aggressive with the years, Oswald funded, in May of 1928, the Review of Cannibalism, a journal that carried the negative and destructive elements of Brazilian Modernism to the ultimate limits and helped to ensure Oswald's becoming 'the enduring playboy of Brazilian letters'".

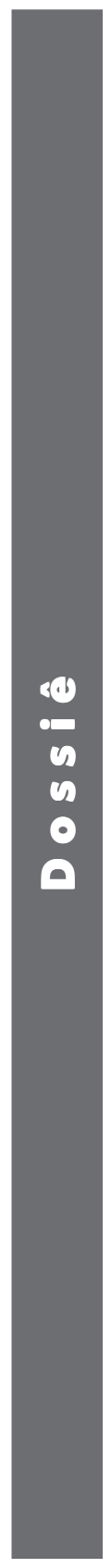

